\title{
UM CAPÍTULO DA HISTÓRIA DO TOMISMO: A TEORIA DO CONHECIMENTO DE TOMÁS DE AQUINO E SUA FONTE IMEDIATA (III).
}

(Continuação).

\section{SEGUNDA PARTE.}

\section{CAPITULO I \\ IMPLICAÇÃO PSICOLÓGICA DA ABSTRAÇÃO.}

Na base da teoria da abstração encontram-se em Santo Alberto os mesmos fatos de consciência que vimos em São Tomás.

Nossa inteligência não é criadora (I Sent., d. 35, a. 1, 2 um contra). Conhecemos as coisas porque são ( $S$. de Cr., II, q. 58, a. 3, 7um contra). A alma por si está em pura potência, de conhecimentos, capaz de tornar-se tudo ("quo est omnia fieri intelligibilia"), mas nada sendo em ato (186). Encontra-se aqui a expressão "tabula rasa" para designar o intelecto em potência (187). $\mathrm{O}$ aperfeiçoamento do intelecto se faz, pois, pela ação dos objetos sôbre êle. Estes objetos se apresentam primeiro à sensação. $O$ que a teoria da abstração deve explicar é a origem das species inteligíveis a partir da experiência sensivel (188). As noções que

\footnotetext{
(186). - I Sent., d. 3, a. 20, quaest. 1; II Sent., d. 3, a. 6. ob. 4; III Sent., d. 13, a. 4 , quaest., d. 14 ; a. 1 , ob. 3 ; $S$. de cr., II, q. 58 , a. 3 , 5 um contra. Ver, entretanto, uma restrição de gue falaremios no capitulo seguinte ( 1 1), mas que não tem conseqüências para a teoria dos dois intelectos.

(187). - S. de cr., I, q. 24, a. 2, c. São Tomás não emprega jamais no Comentário esta expressão, que aparece na Suma Teológica (I, q. 79b a. 2, c.). Ela se acha também no texto do $D e$ ente et essentia editado por $\mathrm{L}$. Baur (c. $5(3)$, p. 45, 1. 20), ao passo que Roland-Gosselin (c. 4, p. 36, 1. 18) a rejeita.

(188). - ". cum enim (ut dicit Avicenna in prima Philosophia) speculativus tantum sit intellectus accipiens, et a corpore et a rebus cognitis, non potest ipse uti in cognoscendo nisi forma abstractionis: quia res non scitur nisi per id quod est natura rei: et hoc non est in nobis, sed oportet a re accipere: ideo est quod abstrahit a re ipsa. Cum autem rei non coniungatur nisi mediantibus corporalibus organis in quibus primum imprimitur forma rei, ideo oportet ipsum etiam posterius accipere a corpore: et sic patet ratio dicti Avicennae, quod speculativus accipit a rebus et a corpore" (I Sent., d. 36 , a. 7 , c.).
} 
temos das coisas se formam no interior de nossa inteligência, o que se evidencia sobretudo no fato de os objetos apreendidos pela sensação serem particulares, singulares, enquanto que os: conceitos são abstratos e universais (189).

\section{$\S 1$ - NECESSIDADE DOS DOIS INTELECTOS.}

O ponto de partida da teoria dał abstração é, pois, para Alberto de Colônia o empirismo tal como se encontra em Tomás de Aquino. O homem deve partir do material sensivel, só inteligivel em potência.

Estamos diante de uma dupla potencialidade.

Em primeiro lugar, a do objeto, que deve sofrer uma transformalção para tornar-se inteligível em ato (190). O conhecimento supõe que a semelhança da coisa a conhecer exista no intelecto (191). Por ela o intelecto torna-se a coisa conhecida, mas só de um certo modo, não completamente. A coisa mesma, em sua própria natureza, não está em nós. E', portanto, uma representação (similitudo) do objeto conhecido por meio de uma species, tendo esta um outro modo de ser no intelecto que o da coisa em si mesma (192). Como se produz esta species, pois que as coisas por si só possuem o modo de ser físico?

Aparece então a cutra potencialidade. A species inteligível em ato precisa atualiz $r$ a determinabilidade da inteligência, capaz de tornar-se tudo. Eis o que Santo Alberto exprime quando diz que é necessário um princípio que una as species ao intelecto ("conjungere intellectui possibili", "uniri ad intelectum possibilem", "imprimere in possibilem", etc.) (193). Atentando para a ima-

\footnotetext{
(189), - Quanto à imanência: S. de cr. II, q. 55, 6um contra; IV Sent., d. 23, a. 16, ad 1. Quanto zo sarátcr abstrato dos conceitos: I Sent., d. 39, a. 9, ad 1,2 .

(190). - "...generans intelligibiliter secundum actum non est in rebus, sed oportet ipsim esse in natura intelligentiae: quia aliter non generaret eam secundum formam intelligibilsm, sed secundum formam rerum" ( $S$. de cr., II, q. 34, a. 1 , ad 3 )

(191). - "Nihil intelligitur nisi per assimilation-m intellizentis et intellecti" ( $S$. de cr. I, o. 24 , a. 1, centra, in fine). "... (ut volunt omnes Philosophi) scienta nihil aliud est quam assimilatio scientis ad rem scitam per rationem sciti et speciem" (I Sent., d. 36, a. 2, ob. 1; cf. ad 1). Ver I Sent., d. 28, a. 10 , ad quaest. 2 ; III, d. 14, a. 2, ob. 2. Quanto ao prinçpio: cogniturm est in cosnoscente secundurm modum cognoscentiss Alberto adota uma fórmula mais próxima da do Liber de causis, donde ela provém: "Et hoc est quod dicit cemmentum in expositione eiusdem propositionis, quod res non recipiunt formas nisi secundum trodum possibilem" ( $S$. de cr., I, q. 24, a. 2 , c., in fine). Cf. S. de cr., II, q. 21 , a. 5 , Ium sontra.

(192). - S. de cr., II, q. 5, 2, ad 4; a. 45, a. 2, ad 1; q. 55, a. 1, 8um contra; q. 57 , a. 2, c.; ad ob.; I Sent., d. 39 , 2.9 , ob. 2 , ad 1 et $2 ;$ d. 37, a. 27 , ad obb. 8-12 (p. 273b); II Sent., d. 3, a. 17, ad quaest. 3; III Sent., d. 24 , a. 1, ob. 2, sed contra (in fine).

(193). - Cf. S. de cr., I, q. 24, a. 1, contra; q. 34, a. 2, c.; III, q. 34, a. 1, 3um contra; q. 55, a 2, ob. 4; II Sent., d. 3, a. 6, ob. 4; III, d. 13, a. 10, quaest.
} 
nência do ato intelectivo, o autor formulc! ainda de outro modo a função dêste princípio: as species devem ser produzidas na inteligência pela ação de um princípio ativo (194).

Dessa forma, as duas potencialidades nos levam a admitir um princípio ativo distinto do intelecto que é tr.bula rasa (intelecto posível, passivel ou hylealis) e capaz de as atualizar (195).

$\mathrm{Na}$ opinião do mestre, tal como na de seu discípulo, esta dualidade de potências deve ser concebida como dois princípios que necessàriamente cooperam na produção do ato único de conhecimento, de sorte que é um absurdo perguntar se o intelecto agente conhece os objetos (196). Rigorosamente falando, quem conhece é a alma intelectiva, que dispõe destas duas potências' necessárias a tôda intelecção (S. de cr., II, q. 55, a. 6, ad 1; ad quaest.).

Como se chega pela ação dos dois intelectos à atualização das duas potencialidades; isto é, à abstração?

A apreensão dos objetos principia, já o dissemos, pela sensação. E' sôbre os dados des potências sensitivas superiores (sentidos internos) (197) que se fará o processo abstrativo. $\mathrm{Na}$ Summa de homine, Alberto estuda minuciosamente estas potências. Explica-nos que a phantasia se diz em dois sentidos. No sentido lato ela abrange três potências: a imrgginatio, a phantasia pròpriamente dita e a aestimatio. Nesta acepção Aristóteles a define: motus a sensu secundum aotum factus. No sentido estrito a fantasia é a potência que sintetiz: $=1$ as imagens sensiveis (198) e chama-se no homem vis cogitativa (segundo Avicena e Algazel). Ordenando as imagens, ela prepara o trabalho do intelecto agente ( $S$. de cr., II, q. 38 , a. 2 , a.; a. 3 , ad ob. 2 ; cf. q. 40 , a. 3, ob.). Por sua vez, a imaginatio pode tomar-se também em dois sentidos. Às vêzes, inclui-se nela a phantasia, como parece fazê-lo Aristóteles; e até a aestimativa; ao passo que, em rigor, a imaginatio é a potência

\footnotetext{
(194). - "...formae educuntur ex ipso per operationem agentis" (S. de cr., I, q. 24 , a. 2 , ad 1 ).

(195) - S, de cr., I, q. 24, a, 1, ob. 2; I Sent., d. 8, a. 25, ob. 5; d. 36, a. 3, ob. 8 ; ad 8 . Ver $S$. de cr., II, q. 55 , a. 1,5 win et 6 um contra: a primeira atualizaça,o, o intelecto possivel a poderia realizar; mas, se efietuasse também a segunda, estaria, sob o mesmo aspecto, em ato e em potência: êle determinaria sıa indeterminação. Cf. ibi., a. 4, ptla. 1, ad 3 .

(196). $\rightarrow$ S. de cr., II, q. 55, a. 1, ad 4: “. .hoc nihil est quicerere, Utrum intellectus agrns recip't speciem. vel intelligit eam... Similiter intellectus agens lumine suo intellectuali operatur unum intelligibile ab uno intellectu possibili, quoá intellectus est agentis et possibilis, sed agentis sicut ab ipso, et poss'bilis sicut in ipso..." Cf. II Sent., d. 3, a. 6, ob. 4 .

(197). - "Partes animae sensibilis quee sunt apprehensivae deintus" (S. de cr., IT q. 37, prol.). Cf. ibid., q. 4, a. 3, 1um sontra; q. 5, a. 2, 4um contra; q. 19, prol.; III Sent., d. 30, a. 4, c.

(198). - ". . potent'a collativa imag num per compositionem et divisionem" ( $S$. de cr., II, q. 38 , a. 1 , c.). Cf. ibid., a. 4, c.
} 
que retém as im‡|gens dos objetos sensiveis quando êstes não mais estão presentes aos sentidos externos (199).

Sendo os fantasmas a matéria preparada para a abstração (cf. S. de cr., II, q. 37, ґ. 4, c.), surge a seguinte questâlo: como o intelecto ativo irá torná-los inteligíveis em ato, pois que os fantasmas, conquanto transcendam já a matéria, ainda se acham na esfera do particular (S. de cr., II, q. 34, a. 3, ad ob. 3; q. 46, ad quaest. 1)?

Santo Alberto, seguindo Aristóteles, serve-se da comparação da luz na percepção visual para explicar a ação do intelecto agente (200). Encontra-se aqui al mesma teoria da ação da luz em relação às côres como a que deparamos em São Tomás; apenas, Alberto se demora mais nesta doutrina e cita as fontes árabes (201). A côr só é visível em potência. A luz torna-a visível em ato, dando-lhe o ser formal de côr, isto é, a luz é como a forma, e as côres exercem a função de matéria (202). Elas recebem um modo de ser dito imaterial e espiritual (203). Sob êsse modo de ser imaterial, as côres atravessam o meio - o transparente, - para influir no órgão da vista (204). E' um modo de ser imperfeito, pois que no meio as côres se acham sòmente em potência (205). Ao passo que seu discípulo designa também por intentio êste estado imperfeito das côres no meio, Alberto Magno reserva o têrmo para o modo de ser das coisas enquanto são princípios de conhecimento (transcendendo, portanto, seu ser material1), conforme a definição que assim formula: "Et voco intentionem speciem quae principium est cognitionis sensibilis" (206). Em outras palavras, a côr é uma intentio quando possui em ato o modo de ser imaterial, informando o órgão da vista para a determinar a ver (207).

\footnotetext{
(199). — S. de cr., II, q. 37 , a. 1, c.; cf. q. 38 , a. 4, c.; I, q. 69, a. 3 , ptla. 3 , quaesitum 2 um, c. p. 710 a). Vimos que São Tomás fala indiferentemente de imaginatio, phandasia e vis cogitativa; êle toma, portanto, fantasia e imaginação no sentido lato, abrangendo em cada uma dessas denominações as duas outras, como Aristóteles no dizer de Alberto Magno.

(200). - "...intellectus agens, ut dicit Philosophus, est ut lumen in visu" ( $S$. de cr., II, q. 55, a. 1 , 9um contra).

(201). - Cf. S. de cr., II, a. 21, a. 3, ptla. 1, ad obb.; a. 5, 2um contra.

(202). - S. de cr., II, q. 27, a. 3, ptla. 3, c. A luz se incorpora na côr, diz ainda em outro lugar (IV Sent., d. 12 , a. 16, 2a. via, ob. 2 et ad 2).

(203). - S. de cr., II, q. 22 , pp. 210-214), et passim. Isso chama-se também abstração (ibid., q. 21 , c; IV Sent., đ. 12, a. 16, 2a. via, ob. 2).

(204). - S. de cr., Ir, a. 26, quaest. 4, obb. 1, 2, ad 1 et 2 . O transparente é também atualizado pela luz ( $S$. de cr., II, q. 21 , a. 4, ad 1), mias nem por isso êle se torna colorido (ibid., q. 34, a. 2, ad quaest.; q. 22 , p. $211 \mathrm{~b}$ ).

(205) . - ". . in transsitu et in fieri" (S. de cr., II, q. 45, a. 2, p. 414b). Cf. q. 21 , a. 5 , ad quaest. (in fine); q. 34, a. 2 , ad quaest.

(206). - S. de cr., II, q. 34 , a. 2, quaest. (p. 298a); cf. q. 45, a. 2, ad 3, ad id

(207). - O duplo modo de ser implica que a intentia, ou a species, é ontoljogicamente distinta da coisa: "In omnibus autem aliud est res, et aliud est intontio ipsius in anima" (I Sent., d. 3, a. 2, ad 2).
} 
A atualizaçãa das côres se faz em virtude de ser a luz a forma própria (acidental) do primeiro móvel - o céu, - forma peia qual se realizam tôdas as transformações no mundo terrestre $(208)$.

Além disso, a luz atualiza a vista, aperfeiçoando-a para que possa ver (209).

São Tomás retomou, pois, de seu mestre a doutrina acêrca da luz que faz as côres em ato.

Alberto critica a opinião de Averroes, segundo a qual a luz é necessária elpenas para tornar o transparente luminoso em ato (210). Tomás de Aquino sòmente em suas últimas obras reparará na teoria de Averroes e a julgará mais conforme com os textos de Aristóteles (cf. nota (28).

Santo Alberto não deixa de prevenir que não se deve dar um sentido espacial à doutrina iexposta, mas, ao contrário, ver nela uma explicação causal (S. de cr., II, q. 22. appendix, ad 8; cf. q. 21 , a. 5 , c.) .

Servindo-se da comparação da luz para explicar o processo abstrativo do intelecto agente, não se deve esquecer, continua 0 autor, que se trata de uma simples comparação, como também no outro exemplo aristotélico da arte em relação à matéria. Em cada uma dessas duas metáforas, a semelh é apenas parcial, ainda que a comparação da luz seja mais apropriada (211).

Com est is restrições, podemos abordar a exposição da abstração intelectual, apoiada quase sempre no primeiro exemplo de Aristóteles.

O intelecto agente tem em si uma luz, que projeta sôbre os fantasmas para extrair dêles (ou abstrair) o inteligível (212). Esta luz diz-se o eto ou mesmo a species de todo inteligivel; o intelecto agente é o constitutivo formal dos inteligíveis enquanto estão em ato, isto é, no modo de ser intencional (primeira atualização) (213). Pela species da coisa tornada inteligivel em ato, $o$ intelecto agente atualiza o intelecto em potência (I Sent., d. 36, a. 3, c.); o intelecto ativio é como a causa eficiente

\footnotetext{
(208). - IV Sent., d. 18, a. 8,; cf. S. de cr., II. q. 19, a. 2, 5um contra; q. 21, a. 1, ad quaest. 1; III Sent., d. 13, a. 11, ed 2 .

(209). - Isso, ela o faz pelas côres, como o diremos logo.

(210). - S. de cr., II, q. 51, a. 3, ptla. 1, 2a diffinitio, 3um et 4 um contra et ad obb.

(211). - S. de cr., II, q. 55, a. 2, ad 1. Em São Tomás, no Comentário, salvo êrro, näo se acha jamais o exemplo da arte.

(212). - I Sent, d. 2, a. 5, 2.; II Sent., d. 8, a. 10, 2 um contra. Ou ainda: fazer brotar o inteligivel (II Sent., d. 7, a. 5, ad quaest. 2).

(213). - S. de cr., II, q. 55, a. ad 5: "Intellectus vero agens... agit... per suam simplicitatem... et illam simplicitatem confert omnibus intelligibilibus". Ibid., 17. a. 3 , ad $17 ;$ q. 55 , a. 5 , ad ob. 2 ; ad quaest. 2 ; a. 6 , ad quaest. 2 ; q. 58 , a. 1 , ad quaest. 1 ; I Sent, d. 35, a. 12 , ad $1 ;$ d. 36, a. 3, c.
} 
e formal que $f \_z$ com que $o$ inteligivel se torne a forma do intelecto possível, o qual por essa razão é comparado com a matéria (214); êle imprime as species abstratas (intentiones ou intentiones rerum) (S. de cr., II, q. 45, a. 2, ad 1; q. 56, a. 3, quaest. 2, ad 3) no intelecto possivel (também: "coniungit cum possibili") (215) (segunda atuəlização). Compete aos fantasmas determinar o intelecto em potência ao conhecimento de tal ou tal coisa (216); êles movem, mas, como sua ação depende da do intelecto agente. exercem um papel instrumental (217). O intelecto atualizado. intellectus in actu (S. de cr., II, q. 55, a. 2, ad 2), cham=r-se também intellectus in habitu ou intellectus formalis, segundo Alexandre de Afrodísia. O autor fala longamente destas denominações e de outras mais, citando os filósofos árabes que as mencionam ( $S$. de cr., II, q. 54).

Certos textos, como se dá com São Tomás, parecem implic $r$ ainda uma outra função do intelecto agente. Assim como a luz atualiza a própria vișta, também o intelecto agente exerce uma certa ação sôbre o intelecto possível para o atuelizar, elevar e iluminar. Isso vem descrito como sends uma atividade espiritual de um intelecto sôbre o outro, o que permite dizer-se que o agente é a forma e o ato do possivel, mas sem trazer a êste nenhum conteúdo determinado. Na realidade, perece que, ainda aqui, não há desacôrdo entre o discípulo e o mestre; trata-se da ação que o agente exerce pela iluminação dos fantasmas, e não de uma influência imediata sôbre o intelecto possível. O mesmo se diga da luz e da vista: esta é atualizada pelas côres iluminadas (218). Mas devese em todo caso convir em que Santo Alberto admitiu uma certa compenetração das du^ls potências, uma atualização habitual do intelecto possível pela luz do intelecto agente (S. de cr., II, q. 55, a.

(214). - S. de cr., II, q. 55, a. 2, ad 1; I Sent., d. 35, a. 2, ad quaest. 3.

(215). - II Sent, d. 8, a. 10, 2 um contra; III Sent., d. 13, a. 10, quaest.

(216). - S. de cr., II, q. 55, a. 2, ad 4: "Similiter est de intellectu possibili; illum enim movet intelectus agens ut agens universale, quod uno modo agit respectu omnium intelligibilium; phantasma autem movet ut agens particulare". Cf. ibid., q. 28 , a. 2 , c.; q. 34 , a. 1,3 um contra; q. 55 , a. 6 , ad quaest. 2; II Sent., d. 4, a. 1, ad quaest. 2 .

(217). - Cf. I Sent., d. 3, a. 29, c. Não encontramos em Santo Alberto a expressão "movens motum" para o fantasma enquanto instrumento do intelecto agente. Mas o intelecto agente é chamado "primum movens" ( $S$. de cr., q. 55, a. 3, ob. 9) e a phantasia "in potentia movens respectu intellectus aglentis" (ibid., a. 6, ad quaest. 2). Nas Sentenças, São Tomás não parece mais cllaro que seu mestre a propósito da função instrumental dos fantasmas. $\mathbf{D a}$ do o contexto doutrinal desta questão, não cremos que o progresso realizado por São Tomás, mesmo nas obras posteriores, seja tão importante como o pensa G. C. REILLY (The Psychology of Saint Albert the Great..., p. 57).

(218). - S. de cr., I, q. 24, a. 2, ad 1 ; II, q. 55 , a. 3 , ob. 11 ; q. 56 , a. 6 , quaest. 1, ad 1; I Sent.., d. 1, a. 15, ad quaest.; d. 2, a. 5, c.; d. 3, a. 29, c.; d. 17 , a. 4 , c.; d. 36 , a. 3 , c.; II Sent., d. 4 , a. 1 , ad quaest. 2 ; IV Sent., d. 18, a. 8, c.; ad 1. Comparar o texto I Sent., d. 1, a. 15, ad quaest. com a passagem de São Tomás no 4.0 livro das Sentenças, q. 2, a. 1, ad 15 . 
6, ad 1, 2; ad ob. 1; I Sent., d. 3, a. 29, c., in fine). São Tomás não parece seguir essa opinião. Numa passagem (I, d. 3, q. 3, a. 5, c.) que lembra os textos de Alberto, o jovem bacharel supõa sempre um conteúdo para que se possa dizer que a luz do intelecto igente está no intelecto possível (ver cap. seguinte, $\S 3$ ).

Há ainda outro ponto onde Alberto não é seguido por seu discípulo: quando reduz a dualidade dos dois intelectos à famosa distinção de quo est e quod est, derivando o intelecto agente do quo est (o ser da alma racional), e o intelecto possível do quod est (o sujeito concreto, substans) (219). Em última análise, acrest centa o autor, pode substituir-se a distinção do quo est e quod est simplesmente pela do ato e potência (220).

Uma vez atualizado o intelecto possível, tôdas as condições exigidas para a intelecção acham-se realizades; êle exerce então sua operação, um juízo ("iudicat de intelligibili") (221). Este juizo tem como objeto, não a species intelligibilis, e sim a própria coisa donde provém a species (222).

Quanto ao verbum, Santo Alberto apresenta uma doutrina ainda menos desenvolvida que a de São Tomás. Para que haja verbum, não basta $o$ ato de intelecção, que consiste na assimilação do inteligível ao sujeito que conhece; é mister tcrescentar-se um aspecto ("addit rationem"): que tal ato se reporte ao objeto corhecido, enquanto expresso, reproduzido pelo espírito. Mais ainda, parece que para Alberto Magno o verbum! implica sempre uma tendência à manifestação da idéiict aos outros (223). Ao passo que para o discípulo a manifestação a si mesmo chega para podermos falar em verbum, para Santo Alberto isso é o simples ato de intelecção e não o verbum (224). A linguagem interior (sermo ou

\footnotetext{
(219). - Santo Alberto daí conclui que o intelecto agente é o princípio do próprio ser do intelecto possível ( $S$. de $c r$, II, q. 55 , a. 5 , ad quaest. 3 ).

(220). - Ver S. de cr., II, a. 55, 2. 4, ptla. 1, Ium contra; c.; ptla. 2, ad 2; a. 6 c.; q. 56, a. 1. ad 1; I Sent., d. 3, a. 33, 4um contra; a. 34, c. Conforme a Sume atribuída a Alexandre de Hales (livro II, 1a. pars, pr 452, sol.), o intelecto agente provém da forma da alma, enquento que o possivel vem de sua matéria. Na recém-descoberta Glossa in quatuor libros Sententiarum, obra autêntica de Alexandre, encontra-se apenas o princípio geral de que em todo ser composto há a dualidade de quo est e quod est; nesta Glassa, além disso, o autor não admite a composição de matéria e forma na alma.

(221). - S. de cr., II, q. 55, a. 4, ptla. 2, ad 3. A própria sénsação já é um juízo (ibid., g. 34 , a. 1 , 3um contra; a. 3, p. 303b). Alberto sublinha muito bem o aspecto de espontaneidade ativa do intelecto possível. Ver ibid., q. 57, a. 1 , ad 2, p. 489a.

(222). - "...si proprie loquamur, species intelligibilis non est materia considerationis circa quam est consideratio, sed potius res cuius est illa species: sicut etiam in visu species visibilis non est materia circa quam est visus, sed potius res visa" (S. de cr.. II, q. 57, a. 1, ad ob. 1).

(223). - "... (conceptio) intentionum illarum quae exprimuntur per linguam" (II Sent., d. 8, a. 3, ob. 2).

(224). - Foi talvez tendo em vista esta afirmação do mestre que São Tomás, em certa passagem, deu a entender que se poderia identificar o verbum com ato de intelecção, pois que para êle o verbum consiste só em uma manifestação a si mesmo (cf. S. Tomás, I, d. 27, q. 2, a. 2, sol. 1, c.) .
} 
dictio interior) exige uma intentio proletionis, uma disposição a ser comunicada a outrem (S. de cr., I, q. 60, a. 2, c., ad 8; I Sent., d. 28, a. 10, ad quaest. 2). Esta disposição se torna efetiva pela linguagem exterior (225).

\section{§ 2. - o INTELECTO POSSÍVEL.}

Estabelecendo de modo perfeitamente paralelo a implicação dos dois intelectos, Alberto de Colônia e Tomás de Aquino chegarão lògicamente às mesmas conseqüências quanto à natureza do intelecto possivel.

Alberto, entretanto, não conhece ainda as opiniões errôneas dos filósofos árabes a $\mathrm{t} \in \mathbb{1}$ respeito. Refere-se apenas vagamente a certos hereges que ensinavam a corruptibilidade da alma humana (S. de cr., II, q. 61, a. 2, sed contra). Quanto a Averroes, êle o cita expressamente em abôno de sua doutrina ( $S$. de cr., II, q. 61, a. 2, cbb. 6, 7; cf. q. 57, a. 3, 2um contra); ignora, pois, completamente que, segundo o Comentador, a inteligência comum da espécie humana é separad;a dos indivíduos.

Para o mestre de São Tomás, como para êste, a alma racional é forma substancial do corpo, seu ato e sua perfeição, apesar de não ser, enquanto rałcional, forma de nenhuma parte do corpo. Isso quer dizer tão sòmente que, considerando-a em suas potências intelectuais, não se pode localizá-las em órgãos determinados. E' uma forma espiritual que tem algumas potências orgânicas e outras que o não são (226). Desnecessário acrescentar que essa doutrinal supõe a distinção real entre a essência $e$ as potências, e implic'a a subsistência da alma como princípio espiritual (cf. I Sent., d. 3, a. 33, ad 2).

\section{§ 3. - o INTELECTO AGENTE E A ILUMINAÇÃo DIVINA.}

Santo Alberto teria ensinado nestas duas grandes obras que o intelecto agente pertence a cada indivíduo humano, tal como o possível, ou era partidário do intelecto agente separado?

As afirmações categóricas do mestre a êsse respeito não deixam subsistir dúvida alguma: o intelecto agente faz perte de cada alma humana, como uma de suas faculdades.

\footnotetext{
(225). - ". . verbum nostrum manifestat nostrum conceptum" (I Sent., d. 27, a. 5, c.). (226). - Ver S. de cr., I, q. 30, a. 2, c.; II, q. 4, a. 1, ad 5, 7; a. 2, ad 7; q. 7, a. 1 , ad ob. 1 ; q. 55, a. 3 , ad 1 ; q. 78 ; I Sent., d. 8, a. 26, quaest. 2. et ad quaest. 2; II Sent., d. 30, a. 1, 3a. via, ad 2; III Sent., d. 15, a. 3, c.; ad 1; IV Sent., d. 23 , ad. 15, ob. 2 .
} 
Mas, as perspectivas históricas acêrca dessal doutrina são bem diferentes das que São Tomás apresenta em seu Comentário das Sentenças. Na Summa de homine (q. 55, a. 3) Alberto Magno se ocupa bastante extensamente com a questão. Enumerab em primeiro lugar, vinte e duas razões contrárias à sua opinião e que tendem a demonstrar que o intelecto agente é uma substância separada ou o próprio Deus. Há alguns argumentos tirrédos de Aristóteles, mas os que têm a palavra são principalmente Avicena e Algazel. A isso o mestre opõe oito razões. A primeira é a passagem onde Aristóteles afirma a necessidłllde, na alma, de um princípio ativo ao lado do intelecto em potência: "necesse est et in anima has esse differentias" (III De anima, cap. 5.430a, 10-14). O segundo argumento provém de Averroes. Os outros sed contra se baseiam em implicações dai teoria da abstração ou em outras doutrinas aristotélicas. No corpo do artigo, enfim, Alberto passa em revista as diversas opiniões dos filósofos. Há, primeiro, os que negam a existência de um intelecto agente. Em seguida, os que a admitem, mas divergindo nal maneira como compreendem a natureza dêsse princípio ativo. Alguns identificam-no com a causa primeira, outros com o hábito dos primeiros princípios ou com o há. bito de tôdas as species inteligiveis; certos filósofos, afinal, como Avicena, fazem dêle uma inteligência separada, al da décima esfera (decimi ordinis). A todos êsses autores nosso escolástico opõe sua meneira de ver. Apoiando-se em Aristóteles e Averroes, nega ser o céu animado por diversas inteligências, excluindo assim o fundamento do sistema emanativo de Avicena. E acrescenta: "Similiter dicimus intellectum agentem humanum esise coniunctum animae humanae, et esse simplicem, et non habere intelligibilia, sed agere ipsa in intellectu possibili ex phantasmatibus, sicut expresse dicit Averroes in commento libri de Anima". Logo, para Santo Aiberto, Averroes seria um partidário da multiplicidade dos intelectos agentes (cf. ad 14; q. 55, a. 1, 2um contra). E' que, como o dissemos acima, Alberto não se tinha ainda apercebido do monopsiquismo do filósofo de Córdova (227). No artigo seguinte (ptla. 1) volta a tratar da questão pelra considerá-la de um ponto de vista puramente especulativo. A conclusão aqui é a mesma, bem como em tôdas as outras passagens onde o problema se põe (228).

Se há, pois, perfeito acórdo entre Tomás e Alberto quanto à doutrina do intelecto agente pessoal, o estado da questão difere

(227). - Cf. D. SALMAN, Note sur la première influence d'Averroès, 1937, pp. 208. 209.

(228). - Ver S. de cr., II, q. 34, a. I. 3um contra; q. 51, ob. 6; q. 54, a. un., c. (p. $451 \mathrm{~b}$ ), ad quaest. 2 ; q. 55, a. 2 , c., ad 1 . 
bastante de um a outro. Em primeiro lugar, o discípulo se encontra num estádio mais avançado no conhecimento do sentido do averroísmo (229). Depois, São Tomás dá mais atenção à teoria de Deus intelecto agente, ao passo que seu mestre não: lhe dá tanta importância. Enfim, parece poder-se afirmer, sem mêdo de errar, que Santo Alberto é mais conseqüente em admitir, claramente e sem reservas, um intelecto potência da alma humana. Com efeito, a dualidade de intelectos é uma implicação da teoriał aristotélica da abstração. Ora, conforme as pressuposições que constituem o ponto de partida desta teoria, não se compreende como se possa chegar à doutrina de um intelecto agente separado. Trita-se de explicar como o homem, que parte do conhecimento dos objetos sensiveis, chega a aprender êsses mesmos objetos num conhecimento espiritual, num ato que se produz no interior de sua inteligência. Para resolver as antinomias que um tal problema epresenta, conclui-se pela existência de duas faculdades, distintas mas inseparáveis. Tendo em vista o que a teoria dos dois intelectos deve explicar, umıj dessas faculdades não teria sentido sem a outra. Foi o mérito de Alberto Magno ter sublinhado esta conseqüência (230), enquanto que São Tomás se deixou influenciar por doutrinas derivadas de sistemas opostos ao seu, doutrinas que o induziram a considerar a possibilidade, ao menos no plano dia psicologia, de um intelecto agente separado.

Vejamos agora qual o pensamento de Santo Alberto a propósito da iluminação divina que sobreviesse à luz do intelecto agente.

Notemos, antes de tudo, que não é fácil discernir o sentido exato de muitas passagens relativas a esta questão. As mais das vêzes parece que o autor fala dos modos de conhecimento superiores à ordem natural. Ora se trata de revelações divin?ls e angélicas ou das más inspirações diabólicas, ora nosso escolástico se coloca no ponto de vista dos filósofos e fala da infusão de idéias pelas inteligências separedas. Há, contudo, textos que visam claramente o conhecimento natural ordinário.

Na Summa de homine, a posição do mestre afigura-se bastante firme. Abordando pela primeira vez o problema, êle o deixa em suspenso, prometendo a solução para mois tarde (231). E' no

\footnotetext{
(229). - Em compensação, Alberto parece ser mais seguro no tocante ao pensamento de Aristóteles. Supõe sempre que o Estagírita fazia do intelecto agente uma faculdade da alma. São Tomás, embora procurando às vêzes interpretar certas passagens de Aristóteles nesse sentido, declara, entretanto, que o filósofo era partidário do intelecto agente separado (II, d. 17, q. 2, a. 1, c.).

(230). $\rightarrow$ Ver II Sent., d. 8, a. 10, c. Cf. S. de cr., II, q. 57, a. 5: Alberto não vê possibilidade de dar um sentido aceitável à teoria de Avicena.

(231). - "Et utrum illa impressio sit opus intellectus agentis vel modi revelationum et prophetiae... modo non determinamus" (S. de cr., II, q. 8, a. 2, ad 5).
} 
artigo acima comentado, a propósito do intelecto agente pessoal (q. 55, a. 3), que Santo Alberto expõe sua opinião. O objetante pretende, com Santo Agostinho em seu De magistro, que nada podemos conhecer sem o concurso do mestre interior que é Deus, e com o Apóstolo (II Cor., c. 3, v. 5), que nada podemos pensar por nós mesmos (obb. 20 e 21). Alberto responde que Agostinho apenas queria dizer que tôda a luz de nossa inteligência vem da causa primeira; portanto, sem Deus, o homem nada poderia conhecer, pois que dêle provém e depende a faculdade de iluminar, própria do intelecto agente (232). Respondendo em seguida à objeção tirelda de São Paulo, o autor distingue: há verdades que não podemos conhecer sem a iluminação da graça, isto é, as verdades sobrenaturais. As que são do domínio da razão, nós as conhecemos por nós mesmos; entretanto, não perfeitamente por nós mesmos, mas pela virtus do intelecto agente, a qual nos foi dada por Deus (233).

A situạ̣ção não é idêntica no Comentário das Sentenças. Se aí se encontram afirmações que se enquadram na mesma ordem de idéias, há contudo uma passagem muito significativa em que Santo Alberto cede ao agostinismo. No princípio do livro I (d. 2, a. 5) o mestre estuda a questão se o homem pode atingir a verdade sem um auxílio especial de Deus. Antes do corpo do artigo vêm as razões em favor da afirmativa (234): o texto do Ambrosiaster: "omne verum a quocumque dicatur est a Spiritu sancto", e o argumento do De mejgistro de Santo Agosirinho (obb. 1 e 3 ). Em seguida, um objetante pretende que não se precisa de uma graça especial para conhecer os primeiros princípios e tudo o que é do domínio das artes liberais. Na solutio, Alberto começa por estabelecer que o conhecimento exige quatro coisas, a saber: o intelecto possível, em potência de conhecer; o intelecto agente, que com sua luz efetua a abstraçäo das species, nas quais se encontra a verdade; a coisa, que constitui o objeto do conhecimento, seja imediatamente, seja por uma imagem, e que é objeto da verdede ("de qua est veritas"); enfim, os princípios, que são como que ins-

\footnotetext{
(232). —Ad aliud dizendum, quod Augustinus in libro de Magistro intendit, quod omne lumen nostri intellectus est a causa prima, et sine ipso nihil possumus facere; sed natura illuminandi super intelligentiam intellectus agentis agit ab ipso et sub ipso" ( $S$. de cr., II, q. 55, a. 3, ad 21). C. ibid., ad 18: "... intellectus agens non est a seipso, nec intelligit a seipso hoc modo quod non sit creatus ab alio, imo est creatus a causa prima: et quod intelfigit, habet a causa prima".

(233). . "...quaedam autem, rationabilia, intelligimus a nobis, sed non quasi ex nobis, sed ex virtute intellectus agentis, quae data est nobis a Deo (ibid., ad 22). Colocarros a palavra "rationabilia" entre vírgulas, como o exige o contexto.

(234). - Santo Alberto inverte freqüentemente a ordem dos argumentos, propondo antes os que são fıvoráveis à soluçăo, e depois as obiectiones in cantrarium (contrárias à opiniāo do autor, 'nesses casos).
} 
trumentos para conhecer e donde provém a verdade. Ora, continua o autor, certos filósofos acreditaram que isso chega para se conhecer ai verdade de ordem racional. Deve-se; porém, dizer que só a luz do intelecto agente não basta sem um acréscimo da luz do intelecto incriado, como a luz do sol se acrescenta à luz das estrêlas (235). Êste lumen divino é o mestre interior de que fa1a Santo Agostinho. Aliás, mesmo certos filósofos ensinaram que nada se conhece senão pela luz primeira. Respondendo à objeção, Santo Alberto nota: se se quiser denominar graça tudo o que Deus nos dá ("quodlibet donum a Deo gratis datum"), nada podemos conhecer sem a graça (236); e, com efeito, um certo filósofo não chegou a afirmar que, conquanto tenhamos um conhecimento habitual, devemos voltar-nos pi|ra a luz do intelecto incriado a fim de conhecer atualmente? (Ver também I Sent., d. 46, a. 19).

Diante de uma exposição tão categórica, não se pode duvidar da mudança de atitude acêrca do ponto em questão. E parece-nos que São Tomás, refutando a doutrina da: iluminação (cf. 1a. parte, cap. I, § 3), tinha diante de si êste artigo de seu mestre. Para justificar seu desacôrdo com Alberto, Tomás de Aquino não se poderia contentar com repetir as idéias expressas pelo mestre no De homine. Eis porque procurou aprofundar a questão, interpretando os textos bíblicos ou agostinizinos no sentido da causalidade divina transcendente, e recorrendo ao argumento da imperfeição de um ser que não é princípio suficiente de sua operação. Tais temas, Santo Alberto já os conhecia (237), mas o discípulo leva-os às últimas conseqüências.

(Conclui no próximo número).

CARLOS LOPES DE MATOS

\footnotetext{
(235). - Para nossos dois escol̄ásticos, as estrêlas recebem sua luz do sol. Uma vez iluminadas, possuem uma luz em si mesmas e irradiam-na por seu turno. Ver: Alberto, II Sent., d. 15, a. 1, ob.; cf. a. 2, c.; S. Tomás, II, d. 13 , q. un., a. 4 , c.; d. 15 , q. 1 , a. 1 , ad 4 .

(?:6). - Cf. II Sent., d. 26, a. 11, sed contra (in initio)

(237). - Cf. S. de cr.o II, q. 54, 2 am divisionem (p. $451 \mathrm{a}$ ); q. 55 , a. 3 , ob. 18 et ad 18; I Sent., d. 37, a. 1, 6um contra; II Sent., d. 24, a. 1; a. 2, ob. 2.
} 